\title{
Optimization of Surface Finish on Grinding Outer Diameter
}

\author{
Durairaj V. P, R. Hariharan, S. Manavalan
}

\begin{abstract}
Grinding is a process of machining to enhance surface performance and achieve a job piece's dimensional precision. It is used as the method of cleaning as well as the primary method of machining. Grinding is generally the last starting procedure to be finished on the job unit and therefore any quality deviations such as geometric mistakes could not be approved on the surface finish for the next procedure. Rughness is one of the key reaction variables in the cylindrical grinding surface. Surface Surface roughness provides the value of the machined ground which is essential to decrease the frictional strength while out-of-roundness is of excellent significance for engines, axles, engines, screw chains, crankshafts, roller engines as out of roundness in these parts can contribute to unnecessary noise, shocks, unit failure, etc. Since we understand that the Taguchi technique used to enhance the performance of manufactured goods is generally chosen to optimize the texture of the surface. Since we worked on single machine, so with that respect this method is best suited as it is a single machine operational method. But machining parameters like wheel grinding rpm, feed rate, concentration of cutting fluid, etc., were constant in industry, and Taguchi method needs variation in such parameters. So due to this impact, this method is neglected and we opt for direct visualization on that particular machine. We took some jobs after certain values that was being grind and with the help of surface roughness tester machine, we took the readings. At some point, we started getting variations and after analyzing we found that particular count and reason which was due to grinding wheel not being dressed after that particular count. With this, the dressing time was reduced and optimization effects was described.

Keywords: Surface finish, ANOVA, RSM
\end{abstract}

\section{INTRODUCTION}

To obtain dimensional accuracy of a work piece and to improve surface quality Grinding is the most popular machining processes. It is the machining method used both as the starting method and as the primary method. Grinding is the initial phase procedure to complete the job and any deviations in performance such as geometric mistakes, the surface finish could not be approved for the next procedure. Surface roughness is one of the performance of the machined ground which is essential to decrease the frictional force while out-of-roundness is of excellent significance in the event of engines, axles, engines, piston locks, crankshafts, roller bearings as it can result in unnecessary noise, vibration, component failure, etc. As we know that Taguchi method, the

Revised Manuscript Received on August 22, 2019.

Durairaj V. P Department of Mechanical Engineering, Bharath Institute of Higher Education and Research, Chennai, Tamilnadu, India.

R. Hariharan, Department of Mechanical Engineering, Bharath Institute of Higher Education and Research, Chennai, Tamilnadu, India.

S. Manavalan, Department of Mechanical Engineering, Bharath Institute of Higher Education and Research, Chennai, Tamilnadu, India. statistical and single machine operational method used to improve the quality of manufactured goods, is usually opt for optimizing the surface finish. Since we worked on single machine, so with that respect this method is best suited. But machining parameters like wheel grinding rpm, feed rate, concentration of cutting fluid, etc., were constant in industry, and Taguchi method needs variation in such parameters. So due to this impact, this method is neglected and we opt for direct visualization on that particular machine and giving an optimization statement for it and its effect without using any method [1-7].

\section{LITERATURE REVIEW}

Lijohn p George, $\mathrm{K}$ varughese job \& IM chandran The test was carried out on MILANO RICEN RUM 1 cylindrical milling device with L9 orthogonal range with varying input device velocity, cutting depth and material strength. MITUTOYO surface sampleSJ-400 surface roughness tester has been used to measure surface roughness. Parametric optimization of Taguchi has been used to optimize the method. The findings were further experiment with confirmation. The impact of cutting, material hardness \& job piece velocity on surface roughness with other parameters laid steady had to be studied in this test. The conclusion of this experiment was : [8-11].

1) Process grinding and different surface roughness parameters are researched and evaluated.

2) Measurement of surface roughness by means of a MITUTOYO surface sample surface roughness tester.

3) Using taguchi optimization method, the optimum value of cut depth, hardness and velocity that provides minimal surface roughness is determined

Ramesh Rudrapati, Ashish Bandyopadhyay\& Pradip Kumar Pal proposed that grinding of stainless steel experiment had been conducted as per L9 orthogonal array of taguchi method. Grey based taguchi method had been used to optimize the grinding parameters to minimize surface roughness parameters $\mathrm{Ra} \& \mathrm{Rq}$ simultaneously. The analysis of single to noise ratio had been applied to investigate the effect of grinding parameters \& optimize them. The optimization methodology used in thepresent study of cylindrical grinding process is very useful to determine the optimum grinding parameters for minimum surface roughness.

Conclusion of this experiment was-

1) From the response table for $S / N$ ratio is found that work speed is the significant factor \& next longitudinal feed followed by in feed on surface roughness.

2) Optimum cutting conditions obtained from the above -said response table, and main effect plot is $\mathrm{A} 1 \mathrm{~B} 3 \mathrm{C} 3$ for simultaneously optimization of surface roughness parameters $\mathrm{Ra}$ 
and $\mathrm{Rq}$ within the experimental range.

1) Proposed GRA cum Taguchi methodology used in the present study is very useful for optimizing the surface roughness parameters $\mathrm{Ra}$ and $\mathrm{Rq}$ simultaneously in the cylindrical Grinding process.

\section{LITERATURE REVIEW-3}

This project study describes the method of surface grinding which is the prevalent method used to create soft finishes on flat surfaces in the manufacturing industry. The Surface production technique is researched in detail with quality and metal extraction levels and these two significant performance features are removed in order to improve the milling process. Many variables such as abrasive wheel grade, wheel velocity, cut depth, table velocity \& material characteristics affect the machining process technique. In this job, sample models are created for surface roughness and metal extraction frequency by using Response Surface as control variables for wheel velocity, table velocity and cut length. RSM has been implemented in this document to determine the optimum parameters of machining to obtain minimum surface roughness and highest metal extraction speed. The EN24 steel procedure is performed. Metal extraction rate (MRR) has been created for the second order mathematical models in terms of machining parameters. The optimization chosen was calculated for validation. The results of the process are tested on output, responses have been established with Analysis Of Variance (ANNOVA) [12].

\section{LITERATURE REVIEW-4 \\ OPTIMIZATION STUDIES ON SURFACE GRINDING PROCESS PARAMETER}

International journal of innovative research in science ,Engineering \& Technology, Vol 4, Issue7, Issan 2347-6710, July 2015

Production of soft surface finishes performs an significant part in the manufacturing sector. For this soft finish, surface grinding method is mostly used in which surface quality and metal extraction frequency are the parameters to be regarded. The economies of the machining method are affected by several variables including cut depth, wheel grade, wheel velocity, material characteristics and table velocity. This article relies primarily on creating empirical models using surface reaction methodology for surface roughness and metal extraction frequency, taking into account control variables such as wheel velocity, table velocity and cut depth. The primary goal of using Response Surface Methodology(RSM) on EN8 Steel's surface grinding procedure is to discover optimal machining parameters that minimize surface roughness and peak metal extraction speed. The second class mathematical models were created based on experimental outcomes for Metal Removal Rates (MRR) and ground roughness, and the models are validated with F-Test. Method Analysis of Variance (ANNOVA) was used to determine the suitability of the designs based on their yield response. This paper attempts to optimize cutting parameters using RSM to use multi-objective features for the models [13].

\section{LITERATURE REVIEW-5}

Sandeep Kumar \& Singh Bhatia proposed that the surface finished can be optimized by using process parameter MRR method. The impact of cylindrical grinding system parameter such as processing wheel velocity, working piece velocity, table velocity, cut depth, situation and optimize surface finish improvement and impact on En15AM steel material extraction frequency. The experiment were conducted on universal cylindrical grinding machine on cylindrical steel rod. Experiment work piece were made from elusion $(0.30 \%-0.40 \%)$, manganese $(1.3 \%-1.7 \%)$, silicon $(0.25 \%)$, Sulpher $\quad(0.12 \%-0.20 \%)$, phosphorous $(0.06 \%)$. The experiment was firstly weight of work piece is measured before machining process with the help of balance, the initial weight of the gap is noted down. Work piece held b/w the two center of grinding machine. Grinding parameter are set according to the orthogonal array. Time taken for each section for grinding is measured. After machining, final weight of the work piece is measured. The result obtained any functional optimization technique. The results for MRR are analyzed using ANNOVA in minimal 17 software [14-18].

The experiment work was conducted that-

1) The depth of cut has least effect on MRR of EM15AM steel.

2) Work piece speed contributes maximum $38.95 \%$ contribution, grinding wheel speed contributes $14.85 \%$, feed rate contribute $12.85 \%$ \&depth of cut has least contribution about $9.80 \%$, towards the MRR method. It means depth of cut has the least effect on MRR.

\section{DIAGRAM}
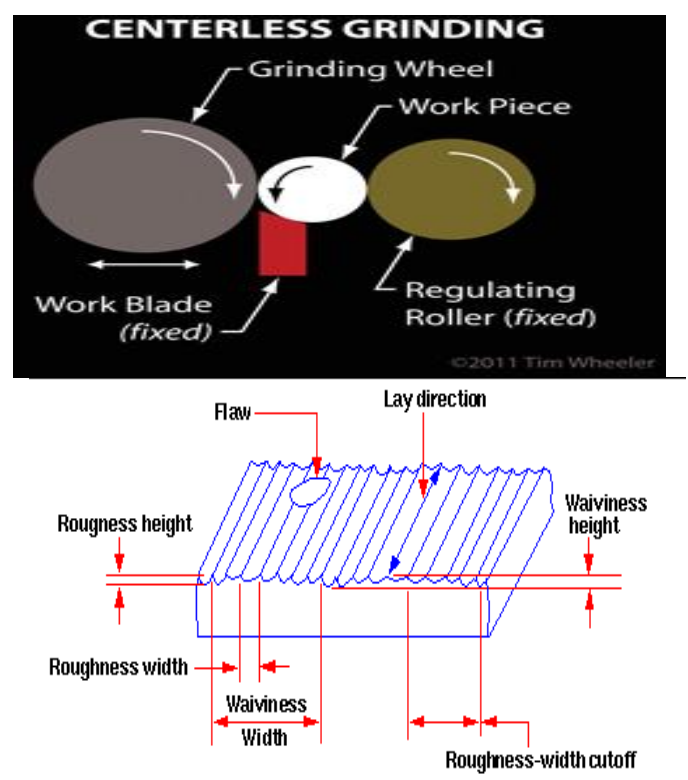

Surface characteristics (Courtesy, ANSI B46.1 - 1962)

\section{METHODOLOGY}

$\begin{array}{ll}\text { 1) ANOVA } & \text { 2) TAGUCHI }\end{array}$

a) Static problem

b) Dynamic problem

\section{RESULTS AND DISCUSSION}

- This project is taken to solve the problem through the methodology of Taguchi method Dynamic problem [19-22].

- The hardness of the shaft is 50 to 60 HRC.

- Surface roughness required

is $\mathrm{Ra} 0.75$ to $\mathrm{Ra} 1.25$

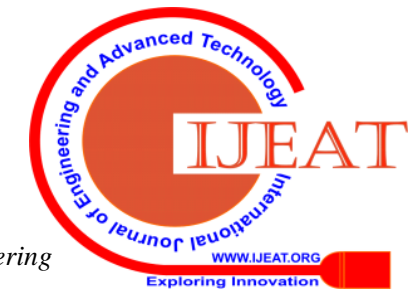


- Considering the dressing factor, as the other factors are running constantly.

- To get the readings, we took five samples \& trials after 300,600 .. up to 1500 , and found that the defect in surface finish was occurring between 1200-1500.

- Again to get perfect visualization, we took another five samples \& trials after 1200,1300 ..up to 1500 and found that the dressing must be done after every 1300 samples instead of 1500 in order to maintain required surface finish parameter. TRAIL 1 (Taken after 500 nos. as random after dressing.)

\begin{tabular}{|c|c|c|}
\hline SL. NO & $\begin{array}{c}\text { IN BETWEEN } \\
\text { 500 AND 1500 }\end{array}$ & $\begin{array}{c}\text { SURFACE } \\
\text { FINISH }\end{array}$ \\
\hline 1 & 550 & RA 1.15 \\
\hline 2 & 625 & RA 1.18 \\
\hline 3 & 750 & RA 2.22 \\
\hline 4 & 850 & RA 2.84 \\
\hline 5 & 1200 & RA 2.68 \\
\hline
\end{tabular}

Reduced the speed of dressing $60 \mathrm{~mm} / \mathrm{sec}$. to $40 \mathrm{~mm} / \mathrm{sec}$. TRAIL 2 (Taken after 300 nos. as random after dressing.)

\begin{tabular}{|c|c|c|}
\hline SL. No & $\begin{array}{c}\text { IN BETWEEN } \\
\text { 300 AND 1200 }\end{array}$ & $\begin{array}{c}\text { SURFACE } \\
\text { FINISH }\end{array}$ \\
\hline 1 & 350 & RA 0.78 \\
\hline 2 & 525 & RA 0.96 \\
\hline 3 & 650 & RA 1.22 \\
\hline 4 & 850 & RA 1.65 \\
\hline 5 & 1200 & RA 1.85 \\
\hline
\end{tabular}

TRAIL 2 (Taken after 300 nos. as random after dressing.)

\begin{tabular}{|c|c|c|}
\hline SL. NO & $\begin{array}{c}\text { IN BETWEEN } \\
\text { 300 AND 1200 }\end{array}$ & $\begin{array}{c}\text { SURFACE } \\
\text { FINISH }\end{array}$ \\
\hline 1 & 330 & RA 0.68 \\
\hline 2 & 540 & RA 0.86 \\
\hline 3 & 680 & RA 1.05 \\
\hline 4 & 920 & RA 1.35 \\
\hline 5 & 1220 & RA 1.56 \\
\hline
\end{tabular}

\section{CONCLUSION}

With this experiment along with trails and some more samples we may conclude with two major decisions.

1. Dressing of the grinding wheel should be in every 1300 nos. then only we can achieve the required roughness on surface of work piece.

2. The speed of dressing speed is to be maintained in between 30 to $40 \mathrm{~mm} / \mathrm{sec}$.

3. Filtering of the coolant should be $5 \mu \mathrm{m}$.

\section{REFERENCES}

1. Tatikonda, N.C. \& Naveenchandran, P. 2019, "The behaviour of a compression ignition engine under the influence of diesel and microalgae biodiesel blends", International Journal of Mechanical and Production Engineering Research and Development, vol. 9, no. 4, pp. 447-456.

2. Tatikonda, N.C. \& Naveenchandran, P. 2019, "An experimental assessment on the impact of injection pressure on the characteristics of a diesel engine powered with the blend of diesel and microalgae biodiesel", International Journal of Engineering and Advanced Technology, vol. 8, no. 6, pp. 3284-3291.

3. Karthikeyan, S., Raman Balasubramanian, S.R., Ramesh, B., Raghul, S. \& Sathish Kumar, S. 2019, "The automatic solar tracker chronicles", International Journal of Recent Technology and Engineering, vol. 8, no. 1, pp. 312-315.

4. Hema, R., Sundararajan, M. \& Balaji, S. 2019, "Smartphone control robot with automatic firing gun", International Journal of Innovative Technology and Exploring Engineering, vol. 8, no. 9 Special Issue 3, pp. 625-627.

5. Saritha, B., Chockalingam, M.P. \& Aswathy, M. 2019, "Degradation of anionic dye using Fe/Tio2 composite by photocatalysis", International Journal of Innovative Technology and Exploring Engineering, vol. 8, no. 9 Special Issue 3, pp. 788-791.

6. Saritha, B., Maria Subashini, L. \& Aswathy, M. 2019, "Utilization of spent coffee grounds for compost production", International Journal of Innovative Technology and Exploring Engineering, vol. 8, no. 9 Special Issue 3, pp. 908-910.

7. Fernando, J.K., Meikandaan, T.P. \& Hemapriya, M. 2019, "Better utilisation of bottom ash in coal fired thermal power station", International Journal of Innovative Technology and Exploring Engineering, vol. 8, no. 9 Special Issue 3, pp. 898-900.

8. Kumar, K.S., Kiruthiga, K. \& Thendral, S. 2019, "Experimental analysis on fractional substitution of bond by utilizing rice husk cinder", International Journal of Innovative Technology and Exploring Engineering, vol. 8, no. 9 Special Issue 3, pp. 1163-1165.

9. Vignesh, P., Madan, P., Mohankumar, D. \& Naveenchandran, P. 2019, "Optimization of four stroke c.i. engine performance by using statistical techniques (mathematical method)", International Journal of Recent Technology and Engineering, vol. 8, no. 2, pp. 1685-1691

10. Bharanidharan, S., Sathiyamurthy, K. \& Sheeba, B. 2019, "Using co-precipitation method determining synthesis and characterization of fe doped zinc oxide nanoparticles", International Journal of Innovative Technology and Exploring Engineering, vol. 8, no. 9 Special Issue 3, pp. 705-707.

11. Jeevanandan, D. \& Vino, J.A. 2019, "Heat recovery from boiler blowdown water by using heat exchanger in thermal power plant", International Journal of Mechanical and Production Engineering Research and Development, vol. 9, no. 3, pp. 219-222.

12. Rakesh, N.L., Balambica, V. \& Kannan, S. 2019, "Biogas extraction from waste orange peel by digestion process", International Journal of Mechanical and Production Engineering Research and Development, vol. 9 , no. 3, pp. 323-330.

13. Meenakshi, C.M. \& Krishnamoorthy, A. 2019, "The mechanical characterization of mono and hybrid fiber reinforced composites using experimental and finite element analysis methods", International Journal of Mechanical and Production Engineering Research and Development, vol. 9, no. 3, pp. 189-196.

14. Mohankumar, D., Prem Jayakumar, M., Sabarsish, R. \& Naveen Chandran, P. 2019, "Modeling and experimental investigation on centrifugal blower by computational fluid dynamics", International Journal of Mechanical and Production Engineering Research and Development, vol. 9, no. 3, pp. 331-340.

15. Balambica, V., Deepak, V. \& Kumar, S. 2019, "Design and efficiency of an asymmetric gear", International Journal of Mechanical and Production Engineering Research and Development, vol. 9, no. 3, pp. 223-230.

16. Manavalan, S., Balakrishnan, G. \& Ramasubramaniam, S. 2019, "An effect of cobalt oxide nano additive with biodiesel blends using cidi diesel engine", International Journal of Mechanical and Production Engineering Research and Development, vol. 9, no. 3, pp. 211-218.

17. Golden Renjith Nimal, R.J., Sivakumar, M. \& Esakkimuthu, G. 2019 , "An investigation on mechanical properties and microstructure of mg/al alloys using $\mathrm{zn}$ interlayer during diffusion bonding", International Journal of Mechanical and Production Engineering Research and Development, vol. 9, no. 3, pp. 125-130. 
18. Hariharan, R., Raja, R. \& Vasu, S. 2019, "Mechanical and tribological behaviour of thin tan coating produced on AISI 1018 substrate by DC magnetron sputtering", International Journal of Recent Technology and Engineering, vol. 7, no. 6, pp. 591-598

19. Manavalan, S., Rai, R., Kumar, R.R., Chaudhary, R.K. \& Chaudhary, S.K. 2019, "Impact of modified piston - A review", International Journal of Recent Technology and Engineering, vol. 8, no. 6, pp. 616-620.

20. Manavalan, S., Gopi, A., Arivarasu, J., Abishek Ahi, A. \& Chandru, S. 2019, "Review on ceramic disc brake system", International Journal of Recent Technology and Engineering, vol. 7, no. 6, pp. 612-615.

21. Sabarish, R. \& Jeya Kumar, M.P. 2019, "The design and analysis of piston - Steady state thermal analysis using "ansys"", International Journal of Mechanical and Production Engineering Research and Development, vol. 9, no. 3, pp. 197-204.

22. Ravi, D. 2019, "CFD simulation of solar loading in car", International Journal of Mechanical and Production Engineering Research and Development, vol. 9, no. 3, pp. 231-236.

\section{AUTHORS PROFILE}

Durairaj V. P Assistant Professor, Department of Mechanical Engineering, Bharath Institute of Higher Education and Research, Chennai, India

R. Hariharan Assistant Professor, Department of Mechanical Engineering, Bharath Institute of Higher Education and Research, Chennai, India

S. Manavalan, Assistant Professor, Department of Mechanical Engineering, Bharath Institute of Higher Education and Research, Chennai, India 